\title{
BITE SIZE: Ethics in publishing
}

Matteo Cavalleri ${ }^{1}$

${ }^{1}$ Affiliation not available

February 18, 2021

\begin{abstract}
Ethical issues in submitting articles, the 5 min version
\end{abstract}

Rich media available at https://speakerdeck.com/teowaits/bite-size-ethics-in-publishing

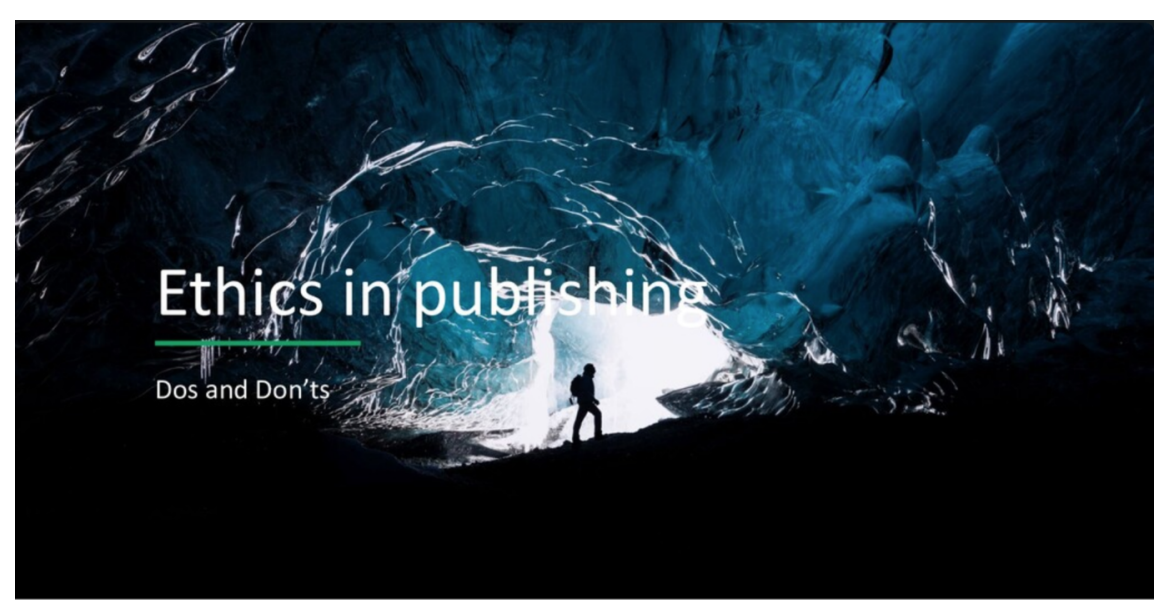

Figure 1: Dos \& Don'ts 